\title{
BMJ Open Psychosocial work characteristics, burnout, psychological morbidity symptoms and early retirement intentions: a cross-sectional study of NHS consultants in the UK
}

\author{
Atir Khan, ${ }^{1}$ Kevin RH Teoh, ${ }^{2}$ Saiful Islam, ${ }^{3}$ Juliet Hassard ${ }^{4}$
}

To cite: Khan A, Teoh KRH, Islam S, et al. Psychosocial work characteristics, burnout, psychological morbidity symptoms and early retirement intentions: a cross-sectional study of NHS consultants in the UK. BMJ Open 2018;8:e018720. doi:10.1136/ bmjopen-2017-018720

Received 2 September 2017 Revised 9 May 2018 Accepted 22 June 2018
Check for updates

(C) Author(s) (or their employer(s)) 2018. Re-use permitted under CC BY-NC. No commercial re-use. See rights and permissions. Published by BMJ.

${ }^{1}$ Diabetes Centre, Glangwili Hospital, Hywel Dda University Health Board, Carmarthen, UK ${ }^{2}$ Department of Organizational Psychology, Birkbeck University of London, London, UK

${ }^{3}$ Swansea Trials Unit, College of Medicine, Swansea University,

Swansea, UK

${ }^{4}$ Centre for Organisational Health and Development, Institute of Mental Health, Division of Psychiatry and Applied Psychology, University of Nottingham, Nottingham, UK

Correspondence to

Dr Atir Khan;

atir.khan45@gmail.com

\section{ABSTRACT}

Objectives The objectives of this study are twofold. First, to examine the direct effect of psychosocial work characteristics (as measured by job autonomy and workrelated pressure) in relation to self-reported psychological morbidity symptoms and early retirement intentions among a sample of hospital consultants in the National Health Service (NHS). Second, to investigate burnout as mediating variable (ie, indirect effect) of these postulated associations.

Design A cross-sectional observational study. Participants 593 NHS consultants (male=63.1\%) from hospitals in England, Scotland and Wales.

Measures Self-reported online questionnaires on work-related pressure and job autonomy (Job DemandsResources Questionnaire); emotional exhaustion and depersonalisation (Maslach Burnout Inventory); depressive and anxiety symptoms (State Trait Personality Inventory) and a single-item on early retirement intention.

Results This study observed high prevalence rates across all adverse health measures: emotional exhaustion (38.7\%), depersonalisation (20.7\%), anxiety symptoms $(43.1 \%)$ and depressive symptoms (36.1\%). Multiple linear regressions examined the postulated direct and indirect effects. Job autonomy had significant negative direct effects on the frequency of NHS consultants' anxiety and depressive symptoms, and their intention to retire early. Both emotional exhaustion and depersonalisation mediated the relationships that work-related pressure (full mediation) and job autonomy (partial mediation) had with self-reported symptoms of psychological morbidities. Only emotional exhaustion mediated the relationships where early retirement intention was the outcome. In terms of sociodemographic factors, age and years' experience predicted both burnout dimensions and psychological morbidity.

Conclusions This is the first study to observe job autonomy to be associated with the number of selfreported psychological morbidity symptoms and early retirement intentions in a sample of NHS consultants. Burnout dimensions mediated these relationships, indicating that interventions need to focus on enhancing working conditions and addressing burnout among NHS consultants before more severe symptoms of psychological morbidity are reported. This study
Strengths and limitations of this study

- This is the first study to demonstrate the mediating role of burnout between psychosocial work characteristics of National Health Service (NHS) consultants and their reported depressive and anxiety symptoms and intentions to seek early retirement.

- Mediations were examined using Hayes' PROCESS Model 4 macro with bootstrapping, which generates more accurate Confidence Intervals than other more commonly used mediation methods.

- This is a cross-sectional study design. As such, any interpretation of causality is not appropriate, as it is plausible that the relationship between the variables measured are reciprocal in nature.

- All study variables were drawn from self-report data of the individual consultant, making it vulnerable to common method bias.

- We were not able determine the response rate as we are unaware as to how many NHS trusts and health boards who agreed to participate actually followed through and sent the survey link to their consultants.

has implications for NHS policy makers and senior leadership.

\section{INTRODUCTION}

The National Health Service (NHS) is one of the world's largest employers, with 1.3 million staff in England and Wales caring for an estimated 243 million patients annually. ${ }^{1}$ For this system to continue to provide safe, sustainable and patient-centred care, the well-being and retention of its workforce are critical considerations. The NHS performs comparatively worse across many measures of staff well-being; with sickness absence rates, on average, 27\% higher than the UK public sector and $46 \%$ higher across all sectors. ${ }^{2}$ Understanding the nature and impact of psychosocial working conditions on medical 
professionals' work-related well-being is, we believe, of clear empirical importance. In addition, its practical value in the development of evidenced-based workplace preventative solutions cannot be understated.

\section{Psychosocial work characteristics and work-related well- being}

Exposure to poor psychosocial work characteristics (eg, poor job autonomy, work-related pressures, injustice at work, insufficient leadership) have been linked to a myriad of work-related well-being (inclusive of physical, psychological, behavioural and attitudinal) outcomes, including, for example, poor mental health ${ }^{34}$; increased health impairing behaviours (eg, increased smoking, ${ }^{5}$ alcohol consumption ${ }^{6}$ ); poor physical health (eg, coronary heart disease) ${ }^{78}$; reduced job satisfaction ${ }^{9}$; intention to quit ${ }^{10}$ and diminished organisational commitment. ${ }^{11}$ In short, there is strong research to suggest that exposure to poor psychosocial work characteristics poses a clear risk to employees' health and work engagement. However, the nature and mechanisms underpinning such associations must be examined and understood at various levels (eg, community, sectoral and organisational), and within various vocational groups and occupational roles. ${ }^{12}$

Within the healthcare sector, much of the available research has focused on a limited number of occupational groups (eg, nurses ${ }^{13} 14$; social workers ${ }^{15} 16$ and, to a lesser degree, doctors ${ }^{17}{ }^{18}$ ). The importance of focusing on different occupational groups is evident in a study of German intensive care units, where nurses, junior physicians and senior physicians reported different levels of burnout, turnover intention and perceived non-beneficial patient treatment. ${ }^{19}$ While the extant literature examining doctors specifically is increasing, there has (to date) been little attempt to examine the nature of this association within a unique vocational subgroup: NHS hospital consultants. These doctors are among the most experienced and trained within this vocational group. ${ }^{20}$ Their role as educators and supervisors of the next generation of doctors and nurses means their organisational contribution in the development of the current and future healthcare workforce is imperative. ${ }^{21}$

\section{The mediating role of burnout}

Burnout is one of the most commonly studied well-being constructs within the healthcare sector ${ }^{22}$; and, in particular, as a measure of work-related well-being among doctors. Burnout refers to a prolonged psychological response to chronic emotional and interpersonal stresses related to work, ${ }^{23} 24$ and manifests through symptoms of emotional exhaustion, depersonalisation and reduced personal accomplishment. Emotional exhaustion denotes being emotionally overextended and exhausted by work. Depersonalisation refers to an impersonal feeling towards people, and reduced personal accomplishment encompasses the reduced work effectiveness due to emotional exhaustion and depersonalisation. Studies ${ }^{22} 2526$ have found strong and consistent support for the emotional exhaustion and depersonalisation dimensional factors of burnout; and are, therefore, typically viewed as its core conceptual components. However, the evidence surrounding professional accomplishment is comparatively mixed. Consequently, personal accomplishment is generally viewed as a separate, but related entity. ${ }^{25}$

Evidence derived from reviews and meta-analyses demonstrate a significant association between poor psychosocial working conditions and doctors' self-reported burnout symptoms. ${ }^{17} 18$ Within the extant literature, burnout has predominantly been conceptualised and investigated as the outcome of a poor psychosocial work environment. However, there is increasing attention being paid to the potential role of burnout as an antecedent to a range of health-related, attitudinal and behavioural outcomes, including: depression and anxiety, ${ }^{27}$ substance abuse, ${ }^{28}$ work performance, ${ }^{29}$ turnover intention ${ }^{30}$ and patient care. ${ }^{31}$ This is not surprising, as burnout depletes workers' energy and coping resources, which may results in increased physiological and psychological strain. ${ }^{32}$ This may, in turn, trigger and exacerbate symptoms of psychological morbidity and work disengagement; and, consequently in the long term, interfere with performance. ${ }^{33}$ The role of burnout has also been examined in relation to turnover intention, notably where healthcare workers' working conditions ${ }^{34}$ and perceived non-beneficial patient treatment ${ }^{19}$ were predictors. Focusing specifically on doctors, to date limited research has sought to examine burnout as a possible mediating variable in relation to doctors' perceived working condition and their psychological health and experienced work-related attitudes. This study aims to address this gap in knowledge.

\section{Study aims}

The objectives of this study are twofold. First, to examine the direct effect of psychosocial work characteristics (job autonomy and work-related pressure) in relation to self-reported psychological morbidity symptoms and early retirement intentions among a sample of hospital consultants in the NHS. Second, to investigate burnout as a mediating variable (ie, indirect effect) of this postulated association. Figure 1 provides a visual representation of the study's postulated direct and indirect effects among independent and dependent variables.

\section{METHOD}

\section{Study design and sample}

A cross-sectional quantitative survey was carried out between November and December 2015. The Human Resources departments of all the Health Boards in Wales $(n=7)$ and Scotland $(n=10)$ were approached to participate in this study, along with 12 NHS Trusts from England. All agreed to forward an electronic survey, administered through Bristol Online Survey, to all their consultants. It is not possible to determine how many consultants actually received the survey. We used the response from a sample size of 500 consultants. This is based on a sample 
Psychosocial Work Characteristics
Burnout Dimensions
Psychological Morbidities
Attitudinal Outcome

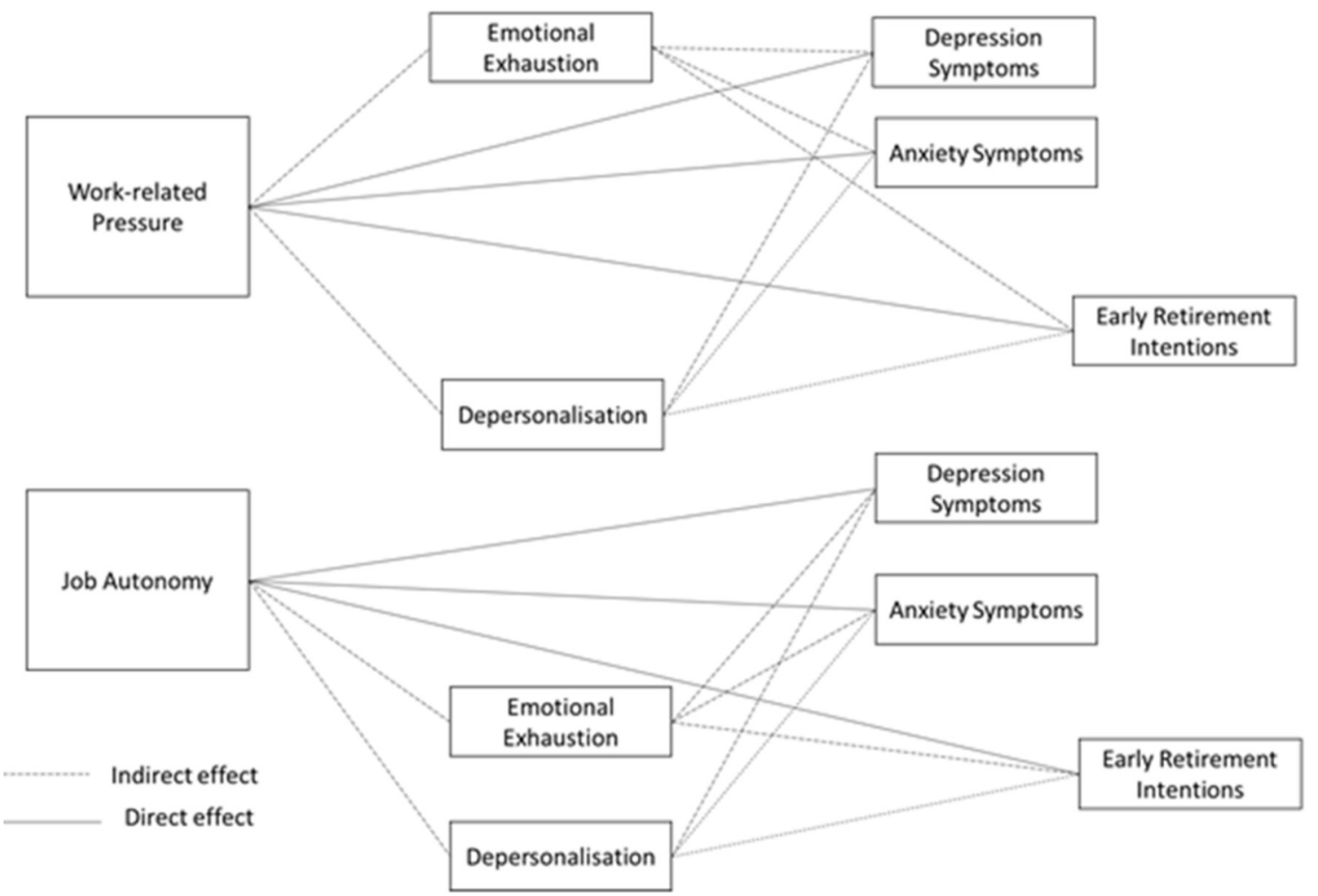

Figure 1 Postulated direct and indirect effects of job autonomy and work-related pressures.

size calculation using survey sample method that considered a total consultant population of 10000 across these Health Board and Trusts (assuming a proportion of $50 \%$, a $95 \%$ CI and allowing $5 \%$ margin of error). The calculation yielded a required sample of 370 responses. This was increased to a larger sample of 500 to obtain better representation of the overall population.

\section{Measures}

Surveyed consultants provided information on sociodemographic details (age, gender, specialty, country, tenure as consultant), work-related pressure, job autonomy, burnout, early retirement intention and anxiety and depressive symptoms.

\section{Psychosocial work characteristics}

Two specific psychosocial work characteristics were examined by the current study: job autonomy and work-related pressure. The decision to examine only two (out of myriad of possible psychosocial work characteristic) was based on what the contemporary literature repeatedly highlights as particularly salient work characteristics to NHS consultants. ${ }^{35-37}$ These also serve as proxies for the two dimensions of the Job Demand-Control Model. ${ }^{38}$ The English version of the Job Demands-Resources Questionnaire $^{39}$ was used to assess work-related pressure and job autonomy. Work-related pressure consisted of four items and job autonomy three items. All items were rated on a Likert scale: 1 (never) to 5 (very often).

\section{Burnout}

The Maslach Burnout Inventory ${ }^{23}$ was used to quantify the two examined dimensions of burnout: emotional exhaustion (nine items) and depersonalisation (five items). Items were rated on a seven-point Likert scale $(0$, 'never' to 6, 'every day'). All subscale items were summed to create two composite scores. Higher scores are indicative of increased emotional exhaustion or depersonalisation. The summed scores on the two used composite measures were used to stratify the sample into 'high' and 'low' reference categories, with established norm scores of health professionals used to inform the categorisation process. ${ }^{40} 41$ A composite score of 27 or higher on the emotional exhausted scale and 13 or higher on the depersonalisation scale were used to categorise participants in the 'high' group. The 'low' group consisted of those with a score of 13 or lower for emotional exhaustion, and 5 or lower for depersonalisation.

\section{Psychological morbidity symptoms}

Symptoms of trait depression and anxiety were measured by the State Trait Personality Inventory. ${ }^{42}$ This 80 -item inventory contains eight scales that measures state and trait-related depression, anxiety, curiosity and anger. Only the 10-item scales pertaining to trait-related depression and anxiety were included in this study. The scales are among the most widely used for anxiety and depression with strong psychometric properties. ${ }^{42-44}$ The frequency 
of each item was rated on a four-point Likert scale (1, 'almost never' and 4, 'almost always'), with high scores representing more frequent experience of anxiety and depressive symptoms. Although neither measure has clinically diagnostic cut-off points, participants in this study with scores higher than the 75th percentile of UK working norm scores were classed as high scoring ( $\geq 18$ for anxiety; $\geq 20$ for depression).

Work-related attitudinal outcome: early retirement intention Depending on the type of scheme, NHS consultants have the option of retiring at age 60 (1995 section) or 65 years (2008 section). Therefore, early retirement intention was assessed through one Likert-based item commonly used in epidemiological surveys of the working population ${ }^{45}$ : "do you think you will be doing this job when you are 60 years old". Anchored from 0 ("I would not even want to be") to 6 'yes'.

\section{Statistical analysis}

Descriptive statistics and study measures' internal consistency using Cronbach's $\alpha$ were analysed. Subsequently, bivariate two-tailed parametric correlations were calculated to examine the statistical association between study variables. Three multiple linear regression models were then carried out to examine the direct effects of the study's predictor variables (job autonomy, work-related pressure, emotional exhaustion and depersonalisation) on the three dependent measures: anxiety and depressive symptoms, and early retirement intention. Two additional multiple linear regressions tested the direct effects that job autonomy and work-related pressure had on emotional exhaustion and depersonalisation. Sociodemographic covariates (age, gender, specialty, country, tenure as consultant) were controlled for. Assumptions underlying multivariate linear regression were assessed by plotting residual errors and standardised residuals. Existence of multicollinearity was checked through variance inflation factors, and Durbin-Watson tests were conducted for correlated residuals. All these diagnostics fell within the acceptable ranges for each multiple linear regression model. SPSS (V.22) was used for data management and statistical analysis. Missing data were examined; with, in general, low levels observed (ie, $1.9 \%$ in gender and $0.7 \%$ for consultant specialty). Such data were excluded from the analysis due their non-significant size.

Hayes ${ }^{46}$ PROCESS Model 4 macro was used to examine the indirect effects that psychosocial work characteristics (ie, job autonomy and work-related pressure) had on consultants' psychological morbidity and turnover intention. Both emotional exhaustion and depersonalisation were examined as mediators within these relationships. This approach tests the indirect effect of both mediators, using a calculation of 1000 bias-corrected bootstrapped 95\% CIs. Bootstrapping estimates model parameters and their SEs by the repeated sampling of the study sample. These do not assume that sampling distributions are normal, which is especially applicable for mediation analyses. ${ }^{47}$ Therefore, bootstrapping generates more accurate CIs than other more commonly used mediation methods. In total, six sets of analyses were carried out, with one set for each relationship between both predictors (work-related pressure, job autonomy) and the three outcome measures (anxiety symptoms, depressive symptoms, early retirement intention). Consultants' gender, age, experience, country and specialty were included as covariates. The paper is reported in accordance with the Strengthening the Reporting of Observational Studies in Epidemiology statement. ${ }^{48}$

\section{Patient and public involvement}

No patients or the public were involved in this study.

\section{RESULTS}

In total, 593 responses were completed. A full demographical breakdown is presented in table 1 . The sample was relatively evenly split between England (32.5\%), Wales (32\%) and Scotland (35.4\%). The majority of respondents were male $(63.1 \%)$, and aged between 41-50 years (45.5\%) and 51-60years (31\%). In total, eight specialty groups were represented, with the majority of respondents identifying as physicians (28.8\%), surgeons $(18.2 \%)$, anaesthesiologists $(14 \%)$ and others $(15.7 \%)$.

Table 1 provides an overview of the proportion of the sample that were categorised as scoring 'high' on the examined study variables. These comparisons are not based on inferential statistics and are only for descriptive purposes. A sizeable proportion of the survey sample reported a high level of depressive and anxiety symptoms. Four out of 10 consultants surveyed reported a high frequency of anxiety symptoms, and over a third of the sample were categorised as having a high degree of depressive symptoms. In relation to burnout, $38.7 \%$ of participants reported a high level of emotional exhaustion and $20.74 \%$ depersonalisation. The means, SD and internal consistency for all study variables are presented in table 2. All used composite measures demonstrated a satisfactory level of internal consistency. Bivariate two-tailed parametric correlations among the predictor and dependent measures are also provided in the same table.

\section{Direct effects between psychosocial work characteristics and} psychological morbidities

Fewer relationships involving sociodemographic variables were found. High frequency of anxiety symptoms associated with older consultants $(\beta=0.17, p<0.01)$, consultants with less experience $(\beta=-0.19, p<0.01)$ and being male $(\beta=-0.12, p<0.01)$. Surveyed consultants from Wales had more frequent anxiety symptoms than compared with those sampled from Scotland $(\beta=-0.08, p<0.05)$. For depressive symptoms, being older $(\beta=0.18, p<0.01)$ and less experienced $(\beta=-0.18, p<0.01)$ was associated with more frequent depressive symptoms. In terms of specialty, 
Table 1 Sample distribution and the proportion of the sample categorised as 'high' on the examined study variables

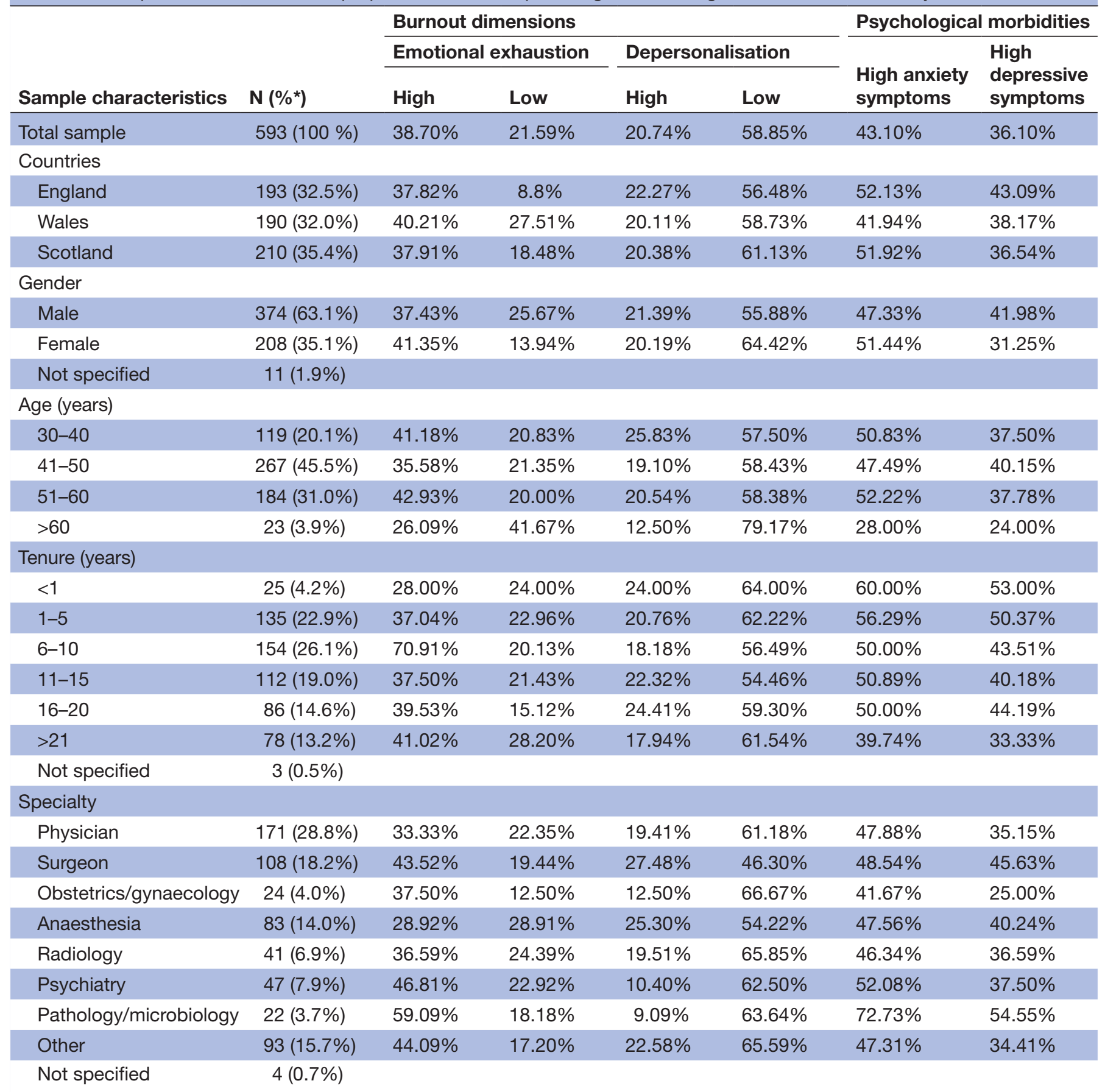

Risk for emotional exhaustion (high $\geq 27$; low $\leq 13$ ) and depersonalisation ( $h i g h \geq 13$; low $\leq 5$ ) was based on composite score on the Maslach Burnout Inventory; high depressive $(\geq 20)$ and anxiety $(\geq 18)$ was based on composite score on the State Trait Personality Inventory representing more frequent experience of symptoms.

${ }^{*}$ After excluding missing values.

obstetrics and gynaecology consultants reported less depressive symptoms $(\beta=-0.08, \mathrm{p}<0.05)$ than physicians. Surveyed consultants' intention to seek early retirement was not associated with any of the sociodemographic variables measured.

Table 3 presents the results from the five multiple linear regression analyses. Consultants' job autonomy negatively predicted the level of consultant's emotional exhaustion $(\beta=-0.26, p<0.01)$ and depersonalisation $(\beta=-0.17, p<0.01)$, as well as the frequency of their anxiety $(\beta=-0.10, p<0.01)$ and depressive $(\beta=-0.17$, $\mathrm{p}<0.01)$ symptoms, and their early retirement intention $(\beta=-0.19, p<0.01)$. Work-related pressure only predicted exhaustion $(\beta=0.38, p<0.01)$ and depersonalisation 


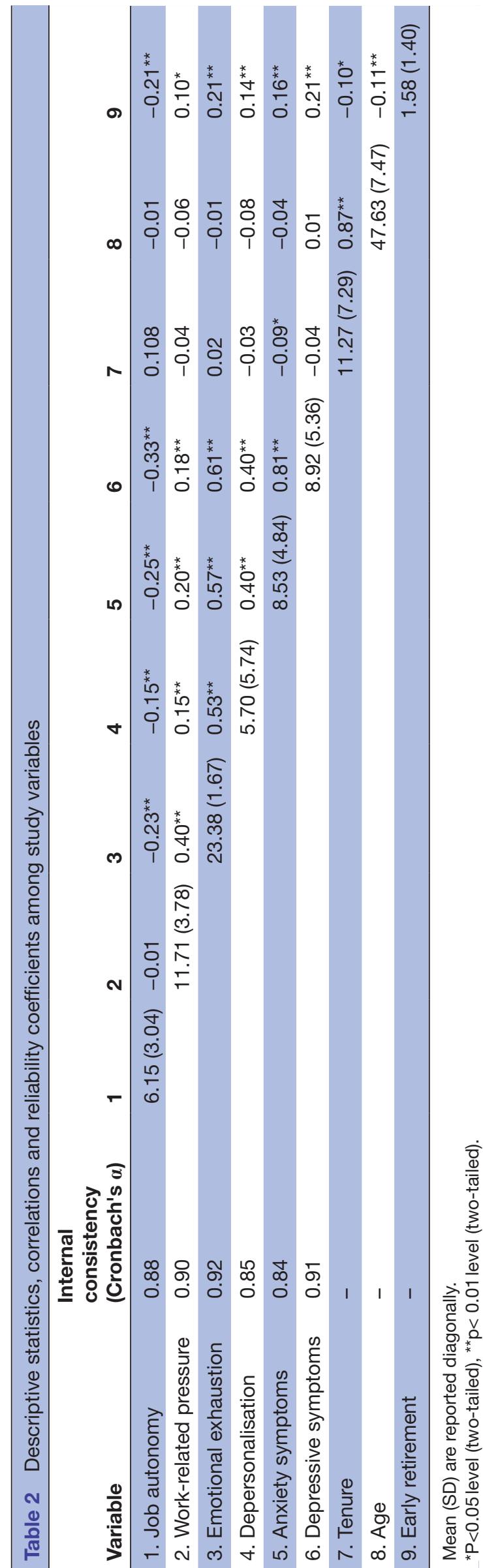

$(\beta=0.14, p<0.01)$, but not any of the other three dependent measures.

\section{Indirect effects between psychosocial work characteristics} and psychological morbidities

In terms of the burnout dimensions, emotional exhaustion positively predicted the frequency of consultants' anxiety $(\beta=0.47, p<0.01)$ and depressive $(\beta=0.54, p<0.01)$ symptoms, and stated intentions to retire early $(\beta=0.13$, $\mathrm{p}<0.05)$. Depersonalisation only predicted anxiety $(\beta=0.16, p<0.01)$ and depressive $(\beta=0.12, p<0.01)$ symptoms. The association between depersonalisation and early retirement intention was not significant.

Six mediation analyses were carried using Hayes ${ }^{46}$ PROCESS macro to examine the mediating role of emotional exhaustion and depersonalisation. Table 4 presents that emotional exhaustion mediated the relationship between job autonomy and all three outcome measures: anxiety $(-0.20(95 \%$ CI -0.27 to -0.12$))$ and depressive symptoms $(-0.24$ (95\% CI -0.33 to -0.15$))$ and early retirement intention (0.02 (95\% CI 0.01 to 0.04$)$ ). Depersonalisation was observed to partially mediate the relationship between job autonomy and anxiety $(-0.05$ $(95 \%$ CI -0.09 to -0.02$))$ and depressive symptoms $(-0.04$ $(95 \%$ CI -0.08 to -0.01$))$. Depersonalisation, however, did not mediate at all the relationship between job autonomy and intentions for early retirement. Comparison of both mediators show that emotional exhaustion was the stronger mediator in relation to anxiety $(-0.15$ $(95 \% \mathrm{CI}-0.23$ to -0.08$))$ and depressive symptoms $(-0.24$ $(95 \%$ CI -0.29 to -0.11$)$ ), but not for early retirement intention (0.02 (95\% CI -0.01 to 0.04$)$ ).

The mediation analyses did not observe any direct effects between work-related pressure and any other three dependent measures. However, evidence of indirect effects among the study variables was observed via both core burnout dimensions (table 5). Emotional exhaustion fully mediated the relationship between work-related pressure and the frequency of consultants' anxiety $(0.25$ (95\% CI 0.18 to 0.33$)$ ) and depressive symptoms $(0.33$ (95\% CI 0.25 to 0.42$)$ ), and stated intentions for early retirement $(0.03$ (95\% CI -0.05 to -0.01$))$. Depersonalisation fully mediated the association between work-related pressures and anxiety $(0.03$ (95\% CI 0.01 to 0.06$))$ and depressive $(0.03$ (95\% CI 0.01 to 0.05$)$ ) symptoms. No indirect effect between work-related pressure and early retirement relationship as mediated by depersonalisation were observed. In all three relationships, emotional exhaustion operated as the stronger mediator: anxiety symptoms (0.22 (95\% CI 0.15 to 0.30$)$ ), depressive symptoms $(0.30$ (95\% CI 0.22 to 0.39$))$ and early retirement intention (0.03 (95\% CI -0.05 to -0.01$)$ ).

\section{DISCUSSION}

A large, and growing, research literature has examined the impact of psychosocial work characteristics in relation to a myriad of work-related well-being measures. ${ }^{57812}$ This 


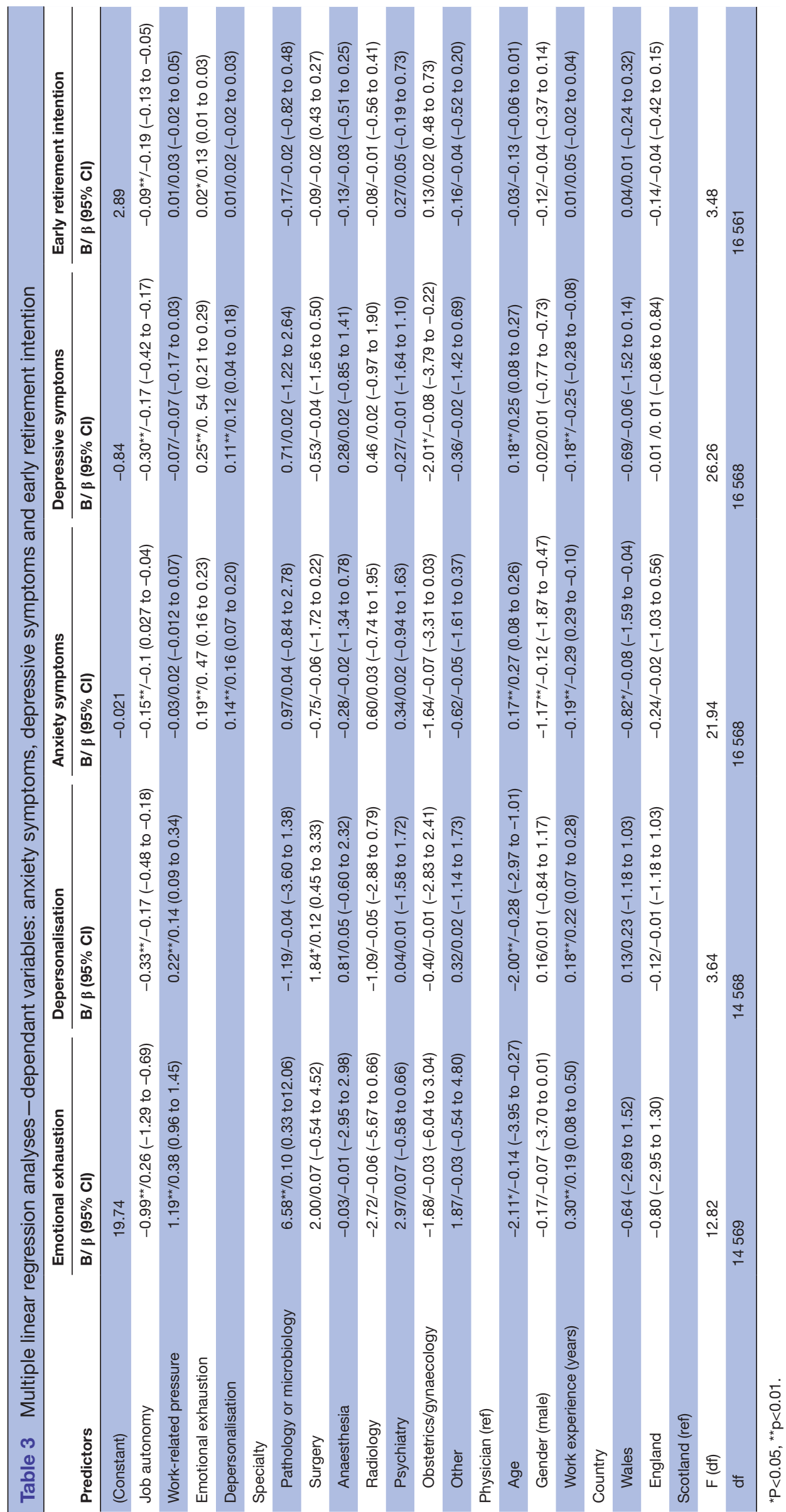


Table 4 Estimated coefficients for mediation model with job autonomy as the predictor

\begin{tabular}{|c|c|c|c|c|c|c|}
\hline Mediator & Outcome & $\begin{array}{l}\text { Effect of } \\
\text { predictor on } \\
\text { mediator (a) }\end{array}$ & $\begin{array}{l}\text { Effect of } \\
\text { mediator on } \\
\text { outcome (b) }\end{array}$ & $\begin{array}{l}\text { Indirect effect } \\
\text { of predictor on } \\
\text { outcome }(a \times b) \text { with } \\
95 \% \mathrm{Cl}\end{array}$ & $\begin{array}{l}\text { Total effect of } \\
\text { predictor on } \\
\text { outcome (c) }\end{array}$ & $\begin{array}{l}\text { Direct effect } \\
\text { of predictor on } \\
\text { outcome (c') }\end{array}$ \\
\hline Depersonalisation & $\begin{array}{l}\text { Anxiety } \\
\text { symptoms }\end{array}$ & $-0.34^{\star \star}$ & $0.14^{\star \star}$ & $-0.05(-0.09$ to 0.02$)$ & & \\
\hline Depersonalisation & $\begin{array}{l}\text { Depressive } \\
\text { symptoms }\end{array}$ & $-0.34^{\star \star}$ & $0.11^{\star \star}$ & $-0.04(-0.08$ to 0.01$)$ & & \\
\hline $\begin{array}{l}\text { Emotional } \\
\text { exhaustion }\end{array}$ & $\begin{array}{l}\text { Early retirement } \\
\text { intention }\end{array}$ & $-1.03^{\star \star}$ & $-0.02^{\star \star}$ & 0.02 (0.01 to 0.04$)$ & $0.11^{* *}$ & $0.09^{* *}$ \\
\hline
\end{tabular}

Gender, age, experience, country and specialty were included as covariates.

${ }^{*} \mathrm{P}<0.05,{ }^{* *} \mathrm{p}<0.01$.

hazard-harm relationship is within the general working population strongly evidenced. However, it is important to understand the nature and driving mechanisms of this hazard-harm association within its given vocational and organisational contexts. ${ }^{22}$ In consideration of this, the current study examined the nature and underpinning mechanisms of such postulated associations within a unique, and grossly under researched vocational group: NHS hospital-based consultants.

Approximately $40 \%$ of this sample were categorised as 'high' on emotional exhaustion, depressive symptoms and anxiety symptoms. These figures are higher than those reported by previous studies of NHS consultants, ${ }^{49-52}$ and are similar to equivalent surveys of junior doctors. ${ }^{1853} \mathrm{It}$ is, however, important to note that these comparison figures are drawn from studies that used different sampling approaches, and different measures for depressive and anxiety symptoms ${ }^{49-51}$ or did not publish the cut-off points used. ${ }^{18} 5253$ The latter is important considering that different studies using the same measures have used different cut-off points from each other. ${ }^{40}$ These descriptive findings highlight the importance of considering the psychological health of doctors (at various stages of their career) as an imperative occupational health issue that necessitates targeted workplace intervention. This descriptive finding highlights, we believe, the importance of considering consultants as a particularly at-risk occupational group in regard to burnout and symptoms of psychological morbidity.

Table 5 Estimated coefficients for mediation model with work-related pressure as the predictor

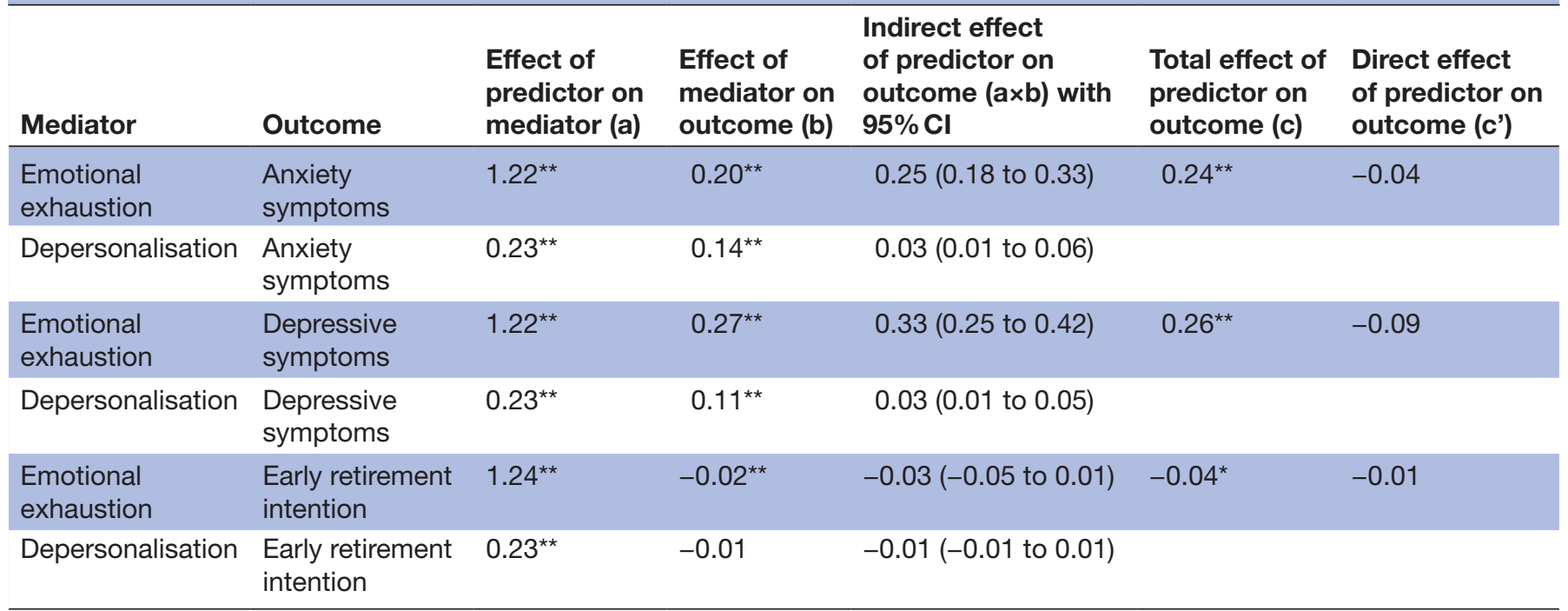

Gender, age, experience, country and specialty were included as covariates.

${ }^{*} \mathrm{P}<0.05,{ }^{\star *} \mathrm{p}<0.01$. 
The negative impact of poor job autonomy and work-related pressures has been strongly evidenced in relation to psychological morbidity symptoms and work-related attitudinal outcomes within the general working population. ${ }^{34910}$ Like previous findings, poor job autonomy was found to directly predict the increased frequency of depressive and anxiety symptoms among surveyed consultants and increased intentions to seek early retirement. Furthermore, this observed association was partially mediated by reported burnout symptoms. According to the conservation of resources theory (COR), ${ }^{54}$ a depletion of energy and coping resources due to burnout can result in a downward spiral that exacerbates resource loss in other areas, including physiological and psychological resources that may trigger depressive and anxiety symptoms. ${ }^{33}$ Similarly, COR theory postulates that when faced with exhaustion, energy depletion and depersonalisation, doctors experiencing burnout may view leaving the profession as a mechanism in which to protect their remaining resources. ${ }^{24}$ Doctors leaving presents a significant loss of skill, knowledge and experience to the health service. $^{3536}$

To our knowledge, this is the first study to examine burnout symptoms (ie, emotional exhaustions and depersonalisation) as a potential mediator between psychosocial work characteristics and psychological morbidity symptoms and work-related attitudinal outcomes as perceived by NHS consultants. However more broadly, these empirical findings contribute to a small, although growing, research domain within the wider burnout literature. It provides evidence of burnout's contributory role to work-related well-being as both an outcome, and an intervening variable. We would speculate that the nature of this association would also, by extension, be predicative of work-related behaviours (eg, leaving the profession) and performance among medical professionals. However, this speculation remains untested but remains an important avenue for future research.

In this study, the surveyed consultants' reported symptoms of emotional exhaustion and depersonalisation were both observed to fully mediate the relationship between their perceived work-related pressures and reported psychological morbidities. This is consistent with previous studies, using nurses ${ }^{34}$ or mixed occupational groups, ${ }^{19}$ that have found burnout to mediate this relationship where turnover intention was the outcome measures. It is important to highlight that the findings derived from the mediation analysis are based on cross-sectional data. However, it does suggest that while excessive and chronic work-related pressures may not be directly associated with surveyed consultants' psychological health, instead it appears that the experience of burnout may play an important role facilitating its detrimental impact. However, it is plausible that the relationship between job autonomy, burnout, depressive and anxiety symptoms and work-related stress may be reciprocal in nature. Therefore, such postulations of directionality and causality require further systematic longitudinal investigation.
Despite the mediating role of the burnout dimensions, depersonalisation did not operate as a mediator where early retirement intention was an outcome. This is perhaps not surprising, as depersonalisation is defined as withdrawal from fully engaging with their current role. ${ }^{22}$ Therefore, it may be that some consultants who cope at work through depersonalisation may be less inclined to see early retirement as a method to leave their work environment, evidenced by an absence of this relationship in the analysis above. Nevertheless, the relationship that depersonalisation has with both depressive and anxiety symptoms suggests that this is not a healthy coping mechanism. It is also plausible that the resource and energy draining nature of emotional exhaustion means it is a stronger driver of NHS consultants looking to retire early.

\section{Practical implications}

Although reviews ${ }^{556}$ have highlighted that individual-level cognitive, behavioural and mindfulness based interventions can be effective in coping with burnout in the healthcare sector, our findings highlight the value of workplace health interventions targeted at adapting working conditions and proactively managing burnout among the NHS staff. One approach to improve the psychosocial work environment is job crafting which has been found to improve medical specialists' well-being and performance. ${ }^{57}$ Sociodemographic variables had some relationship with consultants' psychological morbidity symptoms, which warrants further exploration in future research. Nevertheless, psychosocial work characteristics remain better predictors of the study outcomes used. Consequently, comprehensive interventions that simultaneously target organisational, material and work-time-related conditions may be more beneficial to worker's health, than interventions only targeting the individual. ${ }^{58}$ Government and healthcare leaders need to consider how future organisational decisions in the NHS may further impact on consultants' psychosocial work characteristics and, in turn, their work-related well-being. Although the NHS is under increasing demand and financial strain, greater dialogue between consultants, hospital managers and government officials, at both the local and national level, will go some way in influencing how work-related pressure and job autonomy are perceived and managed. ${ }^{36} 37$

\section{Strengths and limitations}

This study, to the best of our knowledge, is the first to demonstrate the mediating role of burnout between psychosocial work characteristics of NHS consultants and their reported depressive and anxiety symptoms and intentions to seek early retirement. Using a broad range of standard psychometric measures with reported cut-off scores allows for comparison with other studies of this (and other) professional groups. Also, Hayes' PROCESS Model 4 macro with bootstrapping was used to test mediations, which generates more accurate CIs than other more commonly used mediation methods.

In addition to the issue of cross-sectional data already discussed, a number of further limitations need to be 
acknowledged. First, because email invitations were sent via hospitals, we were not able to determine the response rate for this study. The sample size is smaller than that of past research into the prevalence of psychological morbidity among UK consultants. ${ }^{1}{ }^{2}$ This means that generalising this study's findings to the NHS consultant population, or even consultants more broadly, needs to acknowledge these sample and sampling limitations. The second limitation recognises that all study variables were drawn from self-report data of the individual consultant, making it vulnerable to common method bias; but, at the same time, this is an established method in quantitative research. Finally, it is important to reiterate that the measures used for depressive and anxiety symptoms do not reflect a clinical diagnosis of depression and anxiety. Instead, it represents the number of relevant symptoms and, therefore, these prevalence statistics should not be conflated with actual levels of depression or anxiety.

\section{CONCLUSION}

The findings from the current study contribute to the small, but growing research area, namely: the examination of NHS consultants' work-related well-being and the contributing role of their psychosocial working environment. Another important empirical contribution of this study is the observed evidence of experienced burnout symptoms mediating (either partially or fully) the observed relationship between job autonomy and work-related pressures in relation to surveyed consultants' psychological morbidity symptoms. This highlights the salient role of burnout as an intervening variable, and is especially concerning given the high prevalence of consultants scoring as 'high' on the burnout and psychological morbidity symptom measures. These findings emphasise the importance of preventing and mitigating burnout, and the cultivation of skill discretion and autonomy among consultants as an important organisationally focused preventive strategy. This is important for the NHS' ability to provide safe and high-quality care ${ }^{3159}$ and to maintain and retain a healthy and productive workforce. ${ }^{30}$

Acknowledgements The authors would like to thank all those who helped to collect the data. Professor Steve Bain, University of Swansea, was instrumental in making it easier to collect the data from Welsh Health Boards. Professor Graham Leese, University of Dundee, helped to create connections in Scotland to collect data from various hospitals. Consultant colleagues completed the questionnaire, and provided positive feedback to ASAK. The authors would like to thank all human resource officers for helping ASAK to circulate the questionnaire web-link in respective hospitals.

Contributors AK and JH conceived the study concept and design. AK and KT drafted the first version of the manuscript. KT and JH provided critical revision of the manuscript as it went through the revision process. SI and KT did the data management and statistical analyses. All authors contributed to the content and critical revision of the report, and agreed to submit the report for publication.

Funding This study was funded by a study grant from the Research \& Development Department Hywel Dda University Health Board. Publication costs were supported by Hywel Dda University Health Board R\&D Department

Competing interests None declared.

Patient consent Not reqired.
Ethics approval The study received ethical approval from Birkbeck University of London.

Provenance and peer review Not commissioned; externally peer reviewed.

Data sharing statement Individual participant data collected under this study were deidentified which are reported in the form of tables. The original proposal of the study will be available on request. Deidentified data will be shared for non-commercial research purpose given the consent of the lead author after the publications as per guidelines of the BMJ Open.

Open access This is an open access article distributed in accordance with the Creative Commons Attribution Non Commercial (CC BY-NC 4.0) license, which permits others to distribute, remix, adapt, build upon this work non-commercially, and license their derivative works on different terms, provided the original work is properly cited, appropriate credit is given, any changes made indicated, and the use is non-commercial. See: http://creativecommons.org/licenses/by-nc/4.0/.

\section{REFERENCES}

1. NHS Choices. About the national health service (NHS). The NHS in England. www.nhs.uk/ NHSEngland/thenhs/about/Pages/overview. aspx (accessed 8 Jan 2015).

2. Chartered Institute for Personnel Development. Absence management: annual survey report 2013. London, UK: CIPD, 2013.

3. Bonde JP. Psychosocial factors at work and risk of depression: a systematic review of the epidemiological evidence. Occup Environ Med 2008;65:438-45.

4. Stansfeld S, Candy B. Psychosocial work environment and mental health - a meta-analytic review. Scand J Work Environ Health 2006;32:443-62.

5. Kouvonen A, Kivimäki M, Virtanen M, et al. Work stress, smoking status, and smoking intensity: an observational study of 46,190 employees. J Epidemiol Community Health 2005;59:63-9.

6. Kouvonen A, Kivimäki M, Elovainio M, et al. Low organisational justice and heavy drinking: a prospective cohort study. Occup Environ Med 2008;65:44-50.

7. Kivimäki M, Virtanen M, Elovainio $M$, et al. Work stress in the etiology of coronary heart disease-a meta-analysis. Scand J Work Environ Health 2006;32:431-42.

8. Kuper H, Marmot M. Job strain, job demands, decision latitude, and risk of coronary heart disease within the Whitehall II study. $J$ Epidemiol Community Health 2003;57:147-53.

9. Faragher EB, Cass M, Cooper CL. The relationship between job satisfaction and health: a meta-analysis. Occup Environ Med 2005;62:105-12.

10. Wu TY, Fox DP, Stokes C, et al. Work-related stress and intention to quit in newly graduated nurses. Nurse Educ Today 2012;32:669-74.

11. Mathieu JE, Zajac DM. A review and meta-analysis of the antecedents, correlates, and consequences of organizational commitment. Psychol Bull 1990;108:171-94.

12. Teoh $\mathrm{KRH}$, Hassard J, Cox T. Individual and organizational psychosocial predictors of hospital doctors' work-related well-being: A multilevel and moderation perspective. Health Care Manage Rev 2018.

13. Adriaenssens J, De Gucht V, Maes S. Determinants and prevalence of burnout in emergency nurses: a systematic review of 25 years of research. Int J Nurs Stud 2015;52:649-61.

14. Cummings GG, MacGregor T, Davey M, et al. Leadership styles and outcome patterns for the nursing workforce and work environment: a systematic review. Int J Nurs Stud 2010;47:363-85.

15. McFadden $P$, Campbell A, Taylor B. Resilience and burnout in child protection social work: individual and organisational themes from a systematic literature review. Br J Soc Work 2015;45:1546-63.

16. Lloyd C, King R, Chenoweth L, et al. Social work, stress and burnout: a review. J Ment Health 2002;11:255-65.

17. Lee RT, Seo B, Hladkyj S, et al. Correlates of physician burnout across regions and specialties: a meta-analysis. Hum Resour Health 2013;11:48.

18. Prins JT, Gazendam-Donofrio SM, Tubben BJ, et al. Burnout in medical residents: a review. Med Educ 2007;41:788-800.

19. Schwarzkopf $D$, Rüddel $H$, Thomas-Rüddel DO, et al. Perceived nonbeneficial treatment of patients, burnout, and intention to leave the job among icu nurses and junior and senior physicians. Crit Care Med 2017;45:e265-e273.

20. Academy of Medical Royal Colleges. The benefits of consultant delivered care. London, UK, 2012.

21. Peadon E, Caldwell PH, Oldmeadow W. "I enjoy teaching but.": Paediatricians' attitudes to teaching medical students and junior doctors. J Paediatr Child Health 2010;46:647-52. 
22. Schaufeli WB. Burnout in health care. In: Carayon P, eds. Handbook of human factors and ergonomics in health care and patient safety: New York, NY CRC Press, 2007:217-32.

23. Maslach C, Jackson SE. The maslach burnout inventory manual. 2nd edn. Palo Alto, CA: Consulting Psychologists Press, 1986.

24. Maslach C, Schaufeli WB, Leiter MP. Job burnout. Annu Rev Psychol 2001;52:397-422.

25. Schaufeli WB, Taris TW. The conceptualization and measurement of burnout: common ground and worlds apart. Work Stress 2005;19:256-62.

26. Demerouti E, Bakker AB, Nachreiner F, et al. The job demandsresources model of burnout. J Appl Psychol 2001;86:499-512.

27. Hakanen JJ, Schaufeli WB, Ahola K. The Job demands-resources model: a three-year cross-lagged study of burnout, depression, commitment, and work engagement. Work Stress 2008;22:224-41.

28. Lheureux F, Truchot D, Borteyrou X. Suicidal tendency, physical health problems and addictive behaviours among general practitioners: their relationship with burnout. Work Stress 2016;30:173-92.

29. Taris TW. Is there a relationship between burnout and objective performance? A critical review of 16 studies. Work Stress 2006;20:316-34.

30. Tziner A, Rabenu E, Radomski R, et al. Work stress and turnover intentions among hospital physicians: The mediating role of burnout and work satisfaction. Revista de Psicología del Trabajo y de las Organizaciones 2015;31:207-13.

31. Dewa CS, Loong D, Bonato S, et al. The relationship between physician burnout and quality of healthcare in terms of safety and acceptability: a systematic review. BMJ Open 2017;7:e015141.

32. Hobfoll SE, Freedy J. Conservation of resources: a general stress theory applied to burnout. In: Schaufeli WB, Maslach C, Marek T, eds. Professional burnout: recent developments in theory and research. 133. Philadelphia, PA: Taylor \& Francis, 1993.

33. Toker S, Biron M. Job burnout and depression: unraveling their temporal relationship and considering the role of physical activity. $J$ Appl Psychol 2012;97:699-710.

34. Leiter MP, Maslach C. Nurse turnover: the mediating role of burnout. J Nurs Manag 2009;17:331-9.

35. Smith F, Lachish S, Goldacre MJ, et al. Factors influencing the decisions of senior UK doctors to retire or remain in medicine: national surveys of the UK-trained medical graduates of 1974 and 1977. BMJ Open 2017;7:e017650.

36. Walker A, Awad Z, Tolley N, et al. Non-clinical demands are pushing experienced UK surgeons out of the $\mathrm{NHS}^{\dagger}$. Int $\mathrm{J}$ Healthc Manag 2016;9:163-8.

37. Martin G, Sieber S, Howieson B, et al. The changing experience of work of consultants in NHS Scotland, 2015.

38. Karasek RA. Job demands, job decision latitude, and mental strain: implications for job redesign. Adm Sci Q 1979;24:285.

39. Bakker AB. The job demands-resources questionnaire. Rotterdam, the Netherlands, 2014.

40. Doulougeri K, Georganta K, Montgomery A. "Diagnosing" burnout among healthcare professionals: can we find consensus? Cogent Med 2016;3:1-10.
41. Marcelino G, Cerveira JM, Carvalho I, et al. Burnout levels among Portuguese family doctors: a nationwide survey. BMJ Open 2012;2:e001050.

42. Spielberger CD. State-Trait Personality Inventory (STPI) research manual: Mind Garden Inc, 1995.

43. Giesecke T, Williams DA, Harris RE, et al. Subgrouping of fibromyalgia patients on the basis of pressure-pain thresholds and psychological factors. Arthritis Rheum 2003;48:2916-22.

44. Julian LJ. Measures of anxiety: State-Trait Anxiety Inventory (STAI), Beck Anxiety Inventory (BAI), and Hospital Anxiety and Depression Scale-Anxiety (HADS-A). Arthritis Care Res 2011;63(Suppl 11):S467-72.

45. Eurofound. Sixth european working conditions survey - overview report. Luxembourg: publications office of the european union. 2016 http://www.eurofound.europa.eu/european-working-conditionssurveys-ewcs

46. Hayes AF. Introduction to mediation, moderation, and conditional process analysis. New York, NY: Guildford Press, 2013.

47. Shrout PE, Bolger N. Mediation in experimental and nonexperimental studies: new procedures and recommendations. Psychol Methods 2002; 7:422-45.

48. von Elm E, Altman DG, Egger M, et al. Strengthening the Reporting of Observational Studies in Epidemiology (STROBE) statement: guidelines for reporting observational studies. BMJ 2007;335:806-8.

49. Coomber S, Todd C, Park G, et al. Stress in UK intensive care unit doctors. Br J Anaesth 2002;89:873-81.

50. Burbeck R, Coomber S, Robinson SM, et al. Occupational stress in consultants in accident and emergency medicine: a national survey of levels of stress at work. Emerg Med J 2002;19:234-8.

51. Taylor C, Graham J, Potts HW, et al. Changes in mental health of UK hospital consultants since the mid-1990s. Lancet 2005;366:742-4.

52. Ramirez AJ, Graham J, Richards MA, et al. Mental health of hospital consultants: the effects of stress and satisfaction at work. Lancet 1996;347:724-8.

53. Toral-Villanueva R, Aguilar-Madrid G, Juárez-Pérez CA. Burnout and patient care in junior doctors in Mexico City. Occup Med 2009;59:8-13.

54. Hobfoll SE. Social and psychological resources and adaptation. Review of General Psychology 2002;6:307-24.

55. Regehr C, Glancy D, Pitts A, et al. Interventions to reduce the consequences of stress in physicians: a review and meta-analysis. $J$ Nerv Ment Dis 2014;202:353-9.

56. West CP, Dyrbye LN, Erwin PJ, et al. Interventions to prevent and reduce physician burnout: a systematic review and meta-analysis. Lancet 2016;388:2272-81.

57. Gordon HJ, Demerouti E, Le Blanc PM, et al. Individual job redesign: Job crafting interventions in healthcare. J Vocat Behav 2017.

58. Montano D, Hoven H, Siegrist J. Effects of organisational-level interventions at work on employees' health: a systematic review. BMC Public Health 2014;14:135.

59. Hall LH, Johnson J, Watt I, et al. Healthcare staff wellbeing, burnout, and patient safety: a systematic review. PLoS One 2016;11:e0159015-12. 